\title{
An investigation on LED customer' behavior
}

\author{
Samaneh Sadat Khoramgah* and Abbas Saleh Ardestani
}

${ }^{a}$ Department of Management, Tehran Central Branch, Islamic Azad University, Tehran, Iran

\section{H R O N I C L E}

Article history:

Received October 18, 2012

Received in revised format

29 December 2012

Accepted 1 January 2013

Available online

January 162013

Keywords:

Customer behavior

Light Emitting Diode (LED)

Cognitive learning

Perception

\section{A B S T R A C T}

The recent advances in technology have created a challenge for customer on purchasing electronic devises since the cycle of media production such as TV, Mobile devices, etc. are getting short and people need to replace them by new products. The recent emerge of Light Emitting Diode (LED) television has attracted many people and there is a concern to study the impact of important factors on customer behavior in this business. This paper presents an empirical study to study the effects of six variables including customer perception, motivation, cognitive learning, attitude, information and price on customer behavior for LED televisions produced by an Iranian firm in Tehran, Iran. The study designs a questionnaire consists of 27 questions and distributes it among some people who are potential customers of this product. We use multiple regression analysis to study the behavior of different factors on customer behavior. The results of our survey indicate that cognitive learning had the most influencing impact $(0.22)$ on customer behavior followed by price (0.219), motivation (0.203), attitude (0.193), information (0.183) and perception $(0.145)$.

\section{Introduction}

The recent advances in technology have created a challenge for customer on purchasing electronic devises since the cycle of media production such as TV, Mobile devices, etc. are getting short and people need to replace them by new products. The recent emerge of Light Emitting Diode (LED) television has attracted many people and there is a concern to study the impact of important factors on customer behavior in this business. According to Schaeffler (2008), the adoption and growth of digital signage is happening very quickly because the new medium delivers a customized and changeable message, in a completely unique approach, in places people congregate; it also helps great flexibility, while becoming steadily more valuable, attractive, and cost-effective. However, proper growth needs careful attention to guidelines aimed at performing it properly the first time.

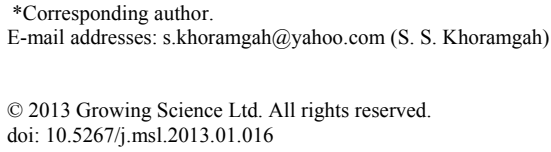


Meldrum and Millman (1991) explained that risk is one of the least understood issues in firms that supply technology-based products and presented 10 most important potential risks facing marketing executives for consideration before any quantitative analysis is performed. Lin et al. (2012) investigated the integration of value-based adoption and expectation-confirmation models in an empirical investigation on IPTV continuance intention. Nambisan and Baron (2007) investigated some interactions in virtual customer environments including product support and customer relationship management.

Saeedni and Khodaei Valahzaghard (2012) presented a study to measure the effect of customer perception, quality, environment concern and satisfaction on green customer loyalty. They considered two hypotheses: the first hypothesis investigated whether the quality of green product had direct influence on customer satisfaction and the second hypothesis studied whether quality of green product had direct influence on customer loyalty. They used sequential equation modeling and the results confirmed both hypotheses.

Azad and Rahimi Shamsabadi (2012) performed an investigation on important factors impacting customer repurchase in a case study of Airline agencies. They reported that while customer perception did not have any relationship with repurchase but it had direct impact on customer's perception and trust. Sehhat (2013) performed a survey on important factors influencing brand equity in a case study of Iranian banking industry. His results indicated that three factors including information, employee job behavior and suggestions and other factor had meaningful effect on customer brand equity. However, the effect of equipment on customer brand equity was not meaningful. Jomehri et al. (2011) did another survey to detect the critical success factors on customer retention on some other Iranian banks. The study confirmed that while none of customer value aspects had direct and positive relationship with customer retention. However, both customer satisfaction and customer loyalty positively and directly affected customer retention.

Sehhat (2012) performed an empirical survey to measure the effect of various factors on the success of electronic marketing. He discussed that internet marketing plays an important role in today business enterprises and studied the impact of five factors namely awareness from the site, site attractiveness, promotional effectiveness, effectiveness and Shopping impacts and effectiveness and loyalty on the success of electronic marketing and confirmed that all five mentioned factors impacted the sales of e-marketing, significantly.

\section{The proposed model}

In this study, we investigate LED customer's behavior in terms of six variables including perception, motivation, learning, attitude, information and price. The proposed study designs a questionnaire consists of 27 questions in Likert scale and distributed it among interested people in LED televisions sold by a domestic assembler in Iran called Pars. Therefore, the study investigations customer behavior (Y) as independent variable and as a function of six independent variables as follows, regression model to study the proposed model,

$Y=\beta_{0}+\beta_{1}$ Perception $+\beta_{2}$ Motivation $+\beta_{3}$ Cognitive learning $+\beta_{4}$ Attitude $+\beta_{5}$ Information $+\beta_{6}$ Price $+\varepsilon$.

The proposed study of this paper considers least square technique to fit the information on the data. In order to validate the questionnaire, first, we have chosen 50 filled questionnaires and tested the data and the results for perception, motivation, cognitive learning, attitude and information are $0.8,0.79$, $0.78,0.81$ and 0.74 , respectively and these results have confirmed the results. Next, we use Pearson correlation analysis to make sure that there is no strong correlation among independent variables. This is important since when there is a strong correlation among independent variables, the results are not reliable. Table 1 demonstrates the results of our findings, 
Table 1

The results of Pearson correlation analysis between each pair of independent variables

\begin{tabular}{cccccccc}
\hline & $\mathrm{Y}$ & $\mathrm{X}_{1}$ & $\mathrm{X}_{2}$ & $\mathrm{X}_{3}$ & $\mathrm{X}_{4}$ & $\mathrm{X}_{5}$ & $\mathrm{X}_{6}$ \\
\hline $\mathrm{Y}$ & 1.000 & $0.603(0.000)$ & $0.591(0.000)$ & $0.799(0.000)$ & $0.701(0.000)$ & $0.574(0.000)$ & $0.771(0.001)$ \\
$\mathrm{X}_{1}$ & $0.603(0.000)$ & $1.000(0.000$ & $0.271(0.000)$ & $0.041(0.000)$ & $0.335(0.000)$ & $0.503(0.000)$ & $0.482(0.000)$ \\
$\mathrm{X}_{2}$ & $0.591(0.000)$ & $0.271(0.000)$ & 1.000 & $0.186(0.000)$ & $0.512(0.000)$ & $0.603(0.000)$ & $0.099(0.002)$ \\
$\mathrm{X}_{3}$ & $0.799(0.000)$ & $0.041(0.000)$ & $0.186(0.000)$ & 1.0000 & $0.332(0.000)$ & $0.519(0.000)$ & $0.387(0.001)$ \\
$\mathrm{X}_{4}$ & $0.701(0.000)$ & $0.335(0.000)$ & $0.512(0.000)$ & $0.332(0.000)$ & 1.000 & $0.449(0.000)$ & $0.632(0.000)$ \\
$\mathrm{X}_{5}$ & $0.574(0.000)$ & $0.503(0.000)$ & $0.603(0.000)$ & $0.519(0.000)$ & $0.449(0.000)$ & 1.000 & $0.447(0.000)$ \\
$\mathrm{X}_{6}$ & $0.771(0.000)$ & $0.482(0.000)$ & $0.099(0.002)$ & $0.387(0.001)$ & $0.632(0.000)$ & $0.447(0.000)$ & 1.000 \\
\hline
\end{tabular}

As we can observe from the results of Table 1, there are some strong correlations between dependent variable, customer behavior, and independent variables. However, there is a weak correlation between each pair of independent variable. Therefore, we could step forward to use regression technique and cautiously make sure that the impacts of weak collinearity between independent variables would nor influence our results, significantly.

\section{The results}

In this section, we present some of the necessary results of the implementation of regression analysis given in Eq. (1). Table 2 shows details of ANOVA test.

Table 2

The results of ANOVA test on regression analysis

\begin{tabular}{llcccc}
\hline Model & Sum of Squares & df & Mean square & F & Sig. \\
\hline Regression & 784.285 & 6 & 130.714 & 468.508 & 0.000 \\
Residual & 277.440 & 993 & 0.279 & & \\
\hline Total & 1061.725 & 999 & & & \\
\hline
\end{tabular}

The results of ANOVA test specifies that the null hypothesis of having no relationship between independent variables (i.e. $\beta_{0}=\beta_{1}=\beta_{2}=\beta_{3}=\beta_{4}=\beta_{5}=\beta_{6}=0$ ) is rejected and we can conclude that there is a linear relationship among independent variables with dependent variable. In addition, adjusted RSquare is equal to 0.684 , which means the regression coefficients could describe approximately $68 \%$ of the changes on customer behavior. Durbin-Watson value is equal to 1.638 , which means there is no auto correlation among residuals. The Sig. value is also equal to zero, which means that the regression model is valid and the results are summarized in Eq. (2) as follows,

$Y=4.957+0.145$ Perception +0.203 Motivation +0.22 Cognitive learning +0.193 Attitude +0.183 Information +0.219 Price $+\varepsilon$

Based on the results, we can conclude that an increase of one unit in customer perception will increase customer behavior by 0.145 , an increase of one unit in customer's motivation will positively influence on customer perception by 0.203. Similarly, cognitive learning will have the most influencing effect on customer behavior (0.22). In addition, customer's attitude, information and price will increase customer behavior by $0.193,0.183$ and 0.219 , respectively.

\section{Conclusion}

In this paper, we have presented an empirical investigation to study the effects of six variables including customer perception, motivation, cognitive learning, attitude, information and price on customer behavior for LED televisions produced by an Iranian firm in Tehran, Iran. The results of our survey have clearly shown that all these factors could influence customer's behavior, positively. In 
this study, cognitive learning had the most influencing impact $(0.22)$ followed by price $(0.219)$, motivation (0.203), attitude (0.193), information (0.183) and perception (0.145).

\section{References}

Azad, N., Rahimi Shamsabadi, M. (2012). An investigation on important factors influencing customer repurchase: A case study of Airline agencies. Management Science Letters, 2(3), 781786.

Jomehri, N., Javanshir, H., Ebrahim Nezhad, S. (2011). An empirical study to determine the critical success factors on customer retention: A case study of Iranian banking sector. Management Science Letters, 1(2), 223-234.

Lin, T.C., Wu, S., Hsu, J.S.C., \& Chou, Y.C. (2012). The integration of value-based adoption and expectation-confirmation models: An example of IPTV continuance intention. Decision Support Systems, 54(1), 63-75

Meldrum, M.J., \& Millman, A.F. (1991). Ten risks in marketing high-technology products. Industrial Marketing Management, 20(1), 43-50.

Nambisan, S., \& Baron, R.A. (2007). Interactions in virtual customer environments: Implications for product support and customer relationship management. Journal of Interactive Marketing, 21(2), 42-62.

Saeedni, H.R., Khodaei Valahzaghard, S. (2012). A study to measure the impact of customer perception, quality, environment concern and satisfaction on green customer loyalty. Management Science Letters, 2(8), 2881-2888

Schaeffler, J. (2008). What's Driving Digital Signage? Digital Signage, 71-100.

Sehhat, S. (2012). An empirical survey to measure the impact of different factors on the success of electronic marketing. Management Science Letters, 2(6), 2187-2192.

Sehhat, S. (2013).A survey on important factors influencing brand equity: A case study of banking industry. Management Science Letters, 3(1), 315-320 